\title{
Article
}

\section{Application of Bayesian network modelling to predict food fraud products from China}

Soon, Jan Mei

Available at http://clok.uclan.ac.uk/32076/

Soon, Jan Mei ORCID: 0000-0003-0488-1434 (2020) Application of Bayesian network modelling to predict food fraud products from China. Food Control, 114. ISSN 0956-7135

It is advisable to refer to the publisher's version if you intend to cite from the work. http://dx.doi.org/10.1016/j.foodcont.2020.107232

For more information about UCLan's research in this area go to http://www.uclan.ac.uk/researchgroups/ and search for < name of research Group>.

For information about Research generally at UCLan please go to http://www.uclan.ac.uk/research/

All outputs in CLoK are protected by Intellectual Property Rights law, including Copyright law. Copyright, IPR and Moral Rights for the works on this site are retained by the individual authors and/or other copyright owners. Terms and conditions for use of this material are defined in the policies page.

\section{CLoK}

Central Lancashire online Knowledge www.clok.uclan.ac.uk

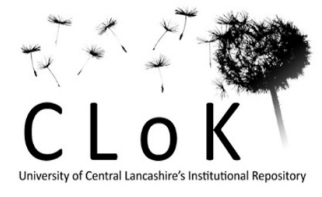




\title{
Chinese consumers' risk mitigating strategies against food fraud
}

\author{
Jan Mei Soon ${ }^{\mathrm{a}, *}$, Xin Liu ${ }^{\mathrm{b}}$ \\ a Faculty of Health and Wellbeing, University of Central Lancashire, Preston, PR1 2HE, UK \\ ${ }^{\mathrm{b}}$ Faculty of Culture and the Creative Industries, University of Central Lancashire, Preston, PR1 2HE, UK
}

\section{A R T I C L E I N F O}

\section{Keywords:}

Food fraud

Insecurity

Risk mitigating strategies

Rural

Self-preservation

Social network

\begin{abstract}
A B S T R A C T
Food fraud is prevalent in China and the increasing number of reported cases undermined the credibility of food safety authorities and the agri-food industry. Food scandals have caused Chinese consumers to be anxious and distrustful of local food products. Urban consumers have resorted to domestic risk mitigating strategies to identify fraudulent food products. This study aims to investigate the risk mitigating strategies against food fraud adopted by urban and rural consumers. Semi-structured interviews $(n=31)$ were conducted to collect data from urban and rural consumers in Beijing and Hebei, China. Three thematic domains and nine sub-themes were identified from the data set. There was a general sense of insecurity, anxiety and disapproval about the state of food products in the country. This has driven distrust in the food system, hence Chinese consumers have developed risk mitigating strategies against purchasing and consuming fraudulent food products. The three main coping approaches include purchasing decision making, information searching \& sharing and daily self-preservation strategies. This is the first study to provide new empirical findings on rural consumers' experiences in dealing with fraudulent products and their risk mitigating strategies against food fraud.
\end{abstract}

\section{Introduction}

Food scandals are not new to Chinese people. Food fraud is defined as the 'deliberate and intentional substitution, addition, tampering, or misrepresentation of food, food ingredients, or packaging; or false or misleading statements made about a product, for economic gain (Spink \& Moyer, 2011). Incidents such as melamine in milk and dairy products, repackaging stale meat for sale in fast food retailers and recycling waste oil from drains and grease traps (gutter oil) resulted in anxiety and lack of trust among Chinese consumers with food industry and the authorities (BBC, 2014; Lu \& Wu, 2014; Pei et al., 2011). This has driven strong political will to revamp the food safety system in China culminating in the National Food Safety Law in 2009 and the 2015 Chinese Food Laws revision (Roberts \& Lin, 2016). Despite these efforts, progress has been limited by the complexity and multiple layers of food safety governance at central, provincial, prefecture and county levels. This is also exacerbated by the massive agri-food industry with over 450,000 food production and processing companies; $75 \%$ of which are small and medium food businesses with less than ten employees (Lam, Remais, Fung, Xu, \& Sun, 2013). China's geographic size and the immense number and diversity of food producers and processors also makes monitoring difficult and costly (Kang, 2019; Yasuda, 2015).

The rise of food safety and fraud awareness among Chinese consumers is evident and have driven consumers to adopt a self-protection mechanism to compensate for the lack of trust in local food. A key example of distrust largely prevails in the dairy industry in China. The entire dairy industry has been 'tainted' and the health and lives of consumers affected (Delman \& Yang, 2012). The melamine milk scandal had prompted the Chinese government to implement various interventions i.e. improved food safety laws, mandate regular and stringent inspections of all food companies, maximum tolerance levels for melamine content were determined and traceability of milk products were emphasised (Li, Sijtsema, Kornelis, Liu, \& Li, 2019; Wei et al., 2020; Wu et al., 2018). Despite the above interventions, it has largely failed to regain Chinese consumers' confidence. To date, the level of trust in domestic infant formula remains low (Kendall et al., 2019; Li, Zhu, Chen, \& Liu, 2019). The growing uncertainties about food safety and fraud issues have produced coping strategies among consumers. A number of studies had investigated Chinese consumers' attitudes to food safety and perceptions towards food fraud (Kendall et al., 2018, 2019; Liu \& Ma, 2016; Liu \& Niyongira, 2017; Zhu, Jackson, \& Wang, 2017) and Kendall et al. (2019) had investigated urban consumers' risk relieving strategies against food fraud. Although Holtkamp, Liu, and McGuire (2014) and Liu and McGuire (2015) had studied the food safety incidents that occurred in rural areas, not many empirical researches have been carried out to investigate the risk mitigating

\footnotetext{
* Corresponding author.

E-mail address: jmsoon@uclan.ac.uk (J.M. Soon).
} 
Table 1

Participants' demographic profile.

\begin{tabular}{|c|c|c|c|c|c|c|c|}
\hline Participant No. & Gender & Age & Locality & Education & Income (CNY) & $\begin{array}{l}\text { Number of household members living } \\
\text { with participant }\end{array}$ & $\begin{array}{l}\text { Frequency of shopping (number of } \\
\text { times per week) }\end{array}$ \\
\hline $\mathrm{P} 1$ & Male & 54 & Urban & Tertiary & $10,000-20,000$ & 3 & 1 \\
\hline $\mathrm{P} 2$ & Female & 33 & Urban & Tertiary & $5000-10,000$ & 3 & 1 \\
\hline P3 & Male & 58 & Urban & Tertiary & $5000-10,000$ & 3 & 2 \\
\hline $\mathrm{P} 4$ & Male & 61 & Urban & Tertiary & $10,000-20,000$ & 2 & $1-2$ \\
\hline P5 & Female & 27 & Urban & Tertiary & $5000-10,000$ & 3 & $2-3$ \\
\hline P6 & Female & 34 & Urban & Tertiary & $10,000-20,000$ & 2 & 2 \\
\hline P7 & Male & 37 & Urban & Tertiary & $10,000-20,000$ & 0 & 2 \\
\hline P8 & Female & 53 & Urban & Tertiary & $10,000-20,000$ & 3 & 1 \\
\hline P9 & Female & 26 & Urban & Tertiary & $5000-10,000$ & 1 & 7 \\
\hline $\mathrm{P} 10$ & Male & 80 & Urban & Tertiary & $10,000-20,000$ & 2 & 1 \\
\hline P11 & Female & 59 & Rural & Secondary & $\leq 5000$ & 2 & 1 \\
\hline P12 & Female & 43 & Rural & Primary & $5000-10,000$ & 1 & $1-2$ \\
\hline P13 & Female & 62 & Rural & $\begin{array}{l}\text { No formal } \\
\text { education }\end{array}$ & $5000-10,000$ & 1 & 0 \\
\hline P14 & Male & 60 & Rural & Primary & $\leq 5000$ & 6 & 2 \\
\hline P15 & Female & 42 & Urban & Tertiary & $10,000-20,000$ & 3 & 2 \\
\hline P16 & Female & 39 & Urban & Tertiary & $5000-10,000$ & 4 & $1-2$ \\
\hline P17 & Female & 23 & Urban & Tertiary & $\leq 5000$ & 0 & 7 \\
\hline P18 & Female & 45 & Urban & Tertiary & $5000-10,000$ & 2 & 2 \\
\hline P19 & Female & 44 & Rural & Secondary & $5000-10,000$ & 3 & 7 \\
\hline $\mathrm{P} 20$ & Male & 46 & Rural & Secondary & $5000-10,000$ & 3 & 7 \\
\hline P21 & Female & 57 & Rural & Secondary & $\leq 5000$ & 2 & 7 \\
\hline $\mathrm{P} 22$ & Male & 64 & Rural & Secondary & $\leq 5000$ & 10 & 7 \\
\hline $\mathrm{P} 23$ & Female & 72 & Rural & Primary & $\leq 5000$ & 2 & $2-3$ \\
\hline $\mathrm{P} 24$ & Female & 58 & Rural & Primary & $\leq 5000$ & 2 & 2 \\
\hline P25 & Female & 70 & Rural & $\begin{array}{l}\text { No formal } \\
\text { education }\end{array}$ & $\leq 5000$ & 1 & 2 \\
\hline P26 & Female & 41 & Rural & Secondary & $\begin{array}{l}\text { No income, supported by } \\
\text { family }\end{array}$ & 4 & 1 \\
\hline P27 & Female & 25 & Rural & Tertiary & $\begin{array}{l}\text { No income, supported by } \\
\text { family }\end{array}$ & 5 & 1 \\
\hline P28 & Female & 35 & Rural & Secondary & $5000-10,000$ & 4 & 2 \\
\hline P29 & Female & 48 & Rural & Secondary & $\begin{array}{l}\text { No income, supported by } \\
\text { family }\end{array}$ & 3 & 7 \\
\hline P30 & Female & 49 & Urban & Tertiary & $5000-10,000$ & 4 & 1 \\
\hline P31 & Female & 55 & Urban & Tertiary & $5000-10,000$ & 2 & 7 \\
\hline
\end{tabular}

strategies against food fraud, particularly among rural consumers.

Klein (2013) and Si, Regnier-Davis, \& Scott (2018) categorised consumers' coping strategies into two major categories (i) food access strategies (e.g. identification and selection of food based on safety, freshness and authenticity) and (ii) food preparation strategies (e.g. washing, soaking and boiling). Liu and Niyongira (2017) found consumers who are concerned about food safety and have higher income often choose to shop at big supermarkets and were willing to purchase higher quality food. Food fraud risk relieving strategies have been documented by Kendall et al. (2018, 2019) and Duggan (2015). Urban consumers rely on self-protection strategies such as information searching, identifying product characteristics, purchasing from large retailers and opting organics and cooking at home. As urban consumers have easier access to food products and are connected to online social network, they can opt to purchase foreign or branded goods from large retailers and utilise online networks to share information. A small proportion of wealthy and more-educated consumers in Beijing use alternative food networks such as renting garden plots for cultivation and participating in community supported agriculture (CSA) where groups of individuals support a farm and share risks and benefits of food production (Zhang, Xu, Oosterveer, \& Mol, 2016).

Zhu et al. (6) reported similar strategies such as observation and judging of grain safety and quality and purchasing of foreign grains among urban consumers. This contradicts rural consumers who prefer domestic grains as their staple food as a show of patriotism. Affordability is another key reason as rural consumers rely on cheaper, local food products compared to imported food (Riccioli et al., 2020). While food safety and fraud are national issues, more than $80 \%$ of food safety incidents originated in rural areas (Holtkamp et al., 2014; Liu \&
McGuire, 2015). For example, most victims of the "big-head disease" (a symptom of acute malnutrition caused by drinking fake milk formula) and milk powder scandals were rural children (Kang, 2019; Watts, 2004). Within the context of food fraud, (i) How do rural Chinese consumers identify and deal with fraudulent products? (ii) What risk mitigating strategies do they employ to protect themselves against fraudulent food products? This study aims to investigate urban and rural consumers' risk mitigating strategies against food fraud.

\section{Methods}

\subsection{Semi-structured interview guide}

The semi-structured interview guide was developed and refined based on literature review. A full discussion guide (for focus group discussion) was also obtained from Kendall et al. (2019). This study selected four food and drink categories in China i.e. rice, infant formula, peanut oil and liquor ('baijiu') as exhibits to trigger participant's discussion of food fraud. Participants were shown pictures of the food items and were asked if they were familiar with the products and to select a product that they often buy. Once selected, participants were asked to share any concerns about the food safety and quality of the product and experiences of purchasing or consuming a fraudulent form of the food product. These product categories were selected as they represent staples in China and had been affected by food fraud. The interview guide is divided into four sections (i) demographic profile (e.g. age, number of household member living together, frequency of shopping and income level); (ii) opinion of food fraud; (iii) experiences of food fraud; and (iv) risk mitigating strategies against food fraud. The 
protocol was pilot-tested with three Chinese students studying at the authors' university to ensure clarity and relevance with Chinese consumers. Ethical approval for the study was applied and approved by the authors' university (STEMH 1009). The full semi-structured guide and exhibits are available from the first author on request.

\subsection{Data collection}

Semi-structured interviews $(n=31)$ were conducted to collect data from urban and rural consumers. The eligibility criteria to participate in the study were $>18$ years old, aware of food fraud incidents, is the main or joint decision maker for food purchases and/or production in their household and has lived in the neighbourhood for three or more years. Of the 31 participants, 16 are based in urban (Beijing) and 15 in rural areas Langfang, Hebei) (Table 1). Both urban and rural consumers were included to explore the extent of (potentially) different strategies adopted by rural consumers. Interviews took place at workplaces, cafes or restaurants and each interview lasted from 30 to $60 \mathrm{~min}$. The different length of interviews is common practice in qualitative research (Silverman, 2006). Given the limited number of participants, this study aims to provide an in-depth analysis of risk mitigation strategies against food fraud expressed by a relatively small number of participants who are aware of food frauds and are willing to speak about their own risk mitigating strategies and behaviours when identifying and dealing with fraudulent food products. With the participants consent, all interviews were recorded.

\subsection{Thematic analysis}

The audio recordings of the interviews were transcribed. Dara from transcripts were thematically analysed based on Braun and Clarke (2006) and Braun, Clarke, Hayfield, and Terry (2019). In the initial phase, transcripts were read and re-read to familiarise with the data. Descriptive level codes were then applied to text fragments that were considered relevant to the research aim and questions. In the second phase, relationships between descriptive codes were examined to identify broader patterns of the potential sub-themes and themes. Data associated with each sub-themes and themes were reviewed to determine whether the data support the sub-themes and if the sub-themes relate to the main themes (Maguire \& Delahunt, 2017). A final thematic map that illustrates the relationships between the themes is provided in Fig. 1.

\section{Results}

The variance in the participants' demographics is shown in Table 1. Participants' perceptions of food fraud and experiences of food fraud are also presented. Three thematic domains were identified from the data set, including (i) purchasing; (ii) information searching and sharing and (iii) daily self-preservation strategies, along with nine subthemes as shown in Fig. 1.

\subsection{Perceptions of food fraud - sense of insecurity and uncertainty}

Food fraud is defined as the deliberate modification of food products for economic purposes. The participants were informed about the definition of food fraud and examples of fraudulent practices were provided with the help of the exhibits. Participants, in general harbour a negative feeling about the food system in China. There was a general sense of insecurity, anxiety and disapproval about the state of food products in the country. The feelings are exemplified below.

'I guess this is really a matter of honesty and integrity. We are the consumers. Yeah, so we deserve the truth totally from, from scratch, the ingredients, the packaging, the production processes and even the quality control by the manufacturer or the watchdogs, but unfortunately, we are

\author{
short-changed.' (P7, male, 37, urban)
}

'I think food fraud in China is really worrying, When I go shopping I worry that I will buy fakes .... So, I often go to big supermarkets.' (P2, female, 33, urban)

'Food safety problem in China is really serious now ... Emm, for example, we often see some unqualified soy sauce, fake condiments, and vegetables with excessive pesticides and chemical ripeners.' (P19, female, 44, rural) (quite a few rural interviewees mentioned the addition of chemical ripeners, and one mentioned that the vegetables kept growing after being bought and stocked at home).

For participant 29, there was a sense of disapproval, 'Food fraud is disgusting ... These food products are very harmful to people's health, especially children' (P29, female, 48, rural). Most participants were uncertain when it comes to differentiating authentic from fraudulent food products. The uncertainty applied to processed foods especially meat, condiments, spices and beverages. Participants expressed uncertainty when it comes to purchasing of meat and oil and were unsure if the meat had been adulterated, or if the oil had been substituted/blended with gutter oil.

'I don't think I've bought any adulterated meat so far, and even if I did, I wouldn't know how to identify it. I usually buy foods with good outward appearance, but now I heard the many stale foods can be turned into good outward appearance through technical means.' (P21, female, 57, rural)

'I would not like to buy false foods, but it's impossible not to buy them. We don't know where and when we will buy false food. We often buy fraudulent food even in big supermarkets, because we don't know which is authentic and which is fraudulent.' (P1, male, 54, urban)

\subsection{Experiences of food fraud}

Experiences of purchasing, consuming and supplying fraudulent food products were shared by the participants. Most food items include fresh produce, meat products, and liquor purchased from markets or small stores. There were also incidences of shops altering the production and expiry dates and experiences of supplying recycled liquor bottles. Table 2 summarises some of the food fraud experienced by the participants and how they dealt with the affected product. Disposal was the most common action although some participants would consume the product provided it does not affect their health.

\subsection{Purchasing strategies}

Both urban and rural participants rely on conventional food suppliers such as supermarkets to purchase food products. Although the participants preferred to shop from reputable supermarkets, rural participants also have the option to shop directly from farms or vegetable markets. Rural consumers prefer to purchase fresh produce directly from farmers and small vendors who also grew the produce for selfconsumption. All participants exhibited a strong level of trust towards big supermarket and tend to avoid small stores.

'Give me peace of mind and I think it's safe.' (P22, female, 64, rural)

'I go to big supermarkets, they are more reliable and have higher standard. They will have some guarantee.' (P28, female, 35 rural)

'We elderly people are now more willing to choose some big supermarkets for shopping as these supermarkets may strictly abide by the rules and regulations.' (P10, male, 80, urban).

'Will purchase vegetables from farmer's market. They are more reliable as the farmers also consume them.' (P26, female, 41, rural)

There were also differences in terms of food products purchased 


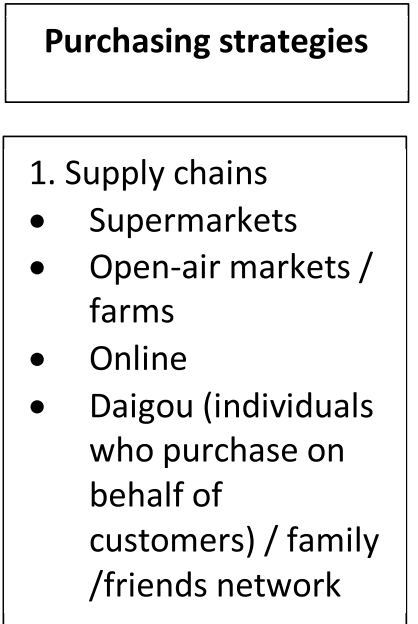

\section{Sensory evaluation}

\section{Imported food}

\section{Avoid promotional items}

\section{Information searching and sharing strategies}

\begin{tabular}{|ll|}
\hline 5. & Product attributes \\
- & Brand loyalty \\
- & Labelling \\
- & Packaging \\
\hline
\end{tabular}

6. Media
- TV, Internet, social
$\quad$ media

7. Peer / family network

\section{Daily self-preservation strategies}

\section{Food production and handling \\ - Home-grown \\ - Home-made \\ - Cleaning practices}

9. Eating out
- Avoid street food
- Trust in prestigious
restaurants or
those with good
reviews and fast
food chain

Fig. 1. Thematic map of consumers' risk mitigating strategies against food fraud.

from the suppliers. Meat and poultry products were often bought from supermarkets rather than open air market. Participants believed that the safety and quality of meat and poultry products were more trustworthy in the supermarkets since the meat products would have been subjected to some form of inspection and quality control. They also believe that it tends to be more hygienic than open-air markets. Whilst selecting food products, some participants rely on sensory evaluation such as visual appearance, texture and smell to purchase meat products and would deliberately select natural looking fresh produce.

'Prefer to buy meat from supermarket and get the receipt.' (P7, male, 37, urban)

'Will not buy meat from open-air market. They tend to sell diseased pork.' (P2, female, 33, urban)

'I will smell the food especially meat to detect if there is any chemical smell. The retailers hate me cause I'm always smelling their stuff.' (P4, female, 61, urban)

'When I buy meat products, I will squeeze the meat to see if it's been injected with water.' (P20, male, 46, rural)

'If a watermelon looks too good when it is not the right season, it must have been drugged, so I usually don't buy it if it looks too good.' (P27, female, 25, rural)

Urban consumers also tend to source for food products from e-retailing websites such as Jindong, COFCO, Timo etc. They also rely on friends and family members who travel abroad to purchase food products especially infant formula and premium food products such as wine and honey. Findings also reveal a lack of trust towards daigou (individuals who shop on behalf of customers). Daigou involves buying products from abroad such as infant formula or health supplements and selling them to customers back in China at a percentage profit (Xie, 2018). There were incidences of daigous asking customers to return empty milk powder cans under the mask of recycling when in fact the packaging will be refilled with inferior milk powder. Rural female consumers do not use daigou services but preferred to purchase milk powder online.

'If I can't get friends to purchase, I will hire a trusted daigou. But there are lots of daigous nowadays who are also fraudsters. They offer a good price to buy back empty milk powder cans.' (P5, female, 27, urban)

'I never trust daigous, so I never use them. If there are some cheating in the process, who will protect the consumers?' (P8, female, 53, urban)

Participants were also hesitant when it comes to purchasing new brands or items that were being promoted. Most urban participants do not trust new brands and would be suspicious if the price is too low whilst rural consumers were more willing to try the new brand if it's cheaper. Participants trust familiar brands and believed that famous brands are more likely to take risk mitigating strategies against fraud. The following were quotes from participants expressing their opinions about promoted items.

'Won't buy it as it's not trustworthy. It's used to sell old stocks and poorquality products.' (P4, female, 61, urban)

'I will be willing to try it if the price is cheaper.' (P28, female, 35, rural)

\subsection{Information searching and sharing strategies}

Participants rely on product attributes such as labelling information and packaging to identify suitable food products for consumption.

Both urban and rural participants would often check the production and expiry dates of food products. Urban consumers often check the manufacturer's details, country of origin and ingredients' list. Urban consumers too are more cautious and observant in scrutinising the labels whilst rural consumers focus more on the shelf life of food products. A recurring theme between urban and rural consumers were their preference for non-genetically modified food products.

'I know of a drink product. It has a similar brand to a famous brand with almost the same characters. There's only a slight change in the character 
Table 2

Experiences of food fraud.

\begin{tabular}{|c|c|c|c|}
\hline Participant & Type of food fraud & $\begin{array}{l}\text { Can you share an experience when you were affected by food } \\
\text { fraud? }\end{array}$ & What did you do with the affected product? \\
\hline $\begin{array}{l}\text { P1, male, } 54, \\
\text { urban }\end{array}$ & Artificial enhancement & $\begin{array}{l}\text { Once, I went to the supermarket and bought some oranges, they } \\
\text { looked nice. According to my shopping experience, if the colour of } \\
\text { the fruit is nice, I'll regard it as good. I came back home and } \\
\text { wanted to eat them. When I washed these oranges, the water } \\
\text { turned orange! Only at that time did I realise that I bought fakes } \\
\text { from the supermarket. }\end{array}$ & $\begin{array}{l}\text { I just threw them away. I might revisit the store again as its near } \\
\text { my home. }\end{array}$ \\
\hline $\begin{array}{l}\text { P4, male, } 62 \text {, } \\
\text { urban }\end{array}$ & Artificial enhancement & $\begin{array}{l}\text { I was deeply affected by an experience of buying a watermelon. } \\
\text { After eating it, I found that my lips turned red. I thought it must } \\
\text { be filled with red dye. Maybe the watermelons were not mature in } \\
\text { that season and the farmer injected some red dye into } \\
\text { watermelons to sell them at higher price. }\end{array}$ & $\begin{array}{l}\text { I felt that it's not worthwhile to go back, so I threw it away. I will } \\
\text { not buy from that stall again. }\end{array}$ \\
\hline $\begin{array}{l}\text { P10, male, } 80 \text {, } \\
\text { urban }\end{array}$ & Mislabelling & $\begin{array}{l}\text { As far as I know, many businesses even postponed the expiry date } \\
\text { of the products. For example, this product was made on the 5th } \\
\text { and the final packages shows that it was made on the } 10 \text { th. I } \\
\text { found it myself. When I went to buy things, the actual date has } \\
\text { not arrived but the production date on the product package was } \\
\text { shown in advance! }\end{array}$ & $\begin{array}{l}\text { So, I always chose carefully to buy dairy products with a } \\
\text { relatively short factory time. }\end{array}$ \\
\hline $\begin{array}{l}\text { P25, female, } 70 \text {, } \\
\text { rural }\end{array}$ & Mislabelling & $\begin{array}{l}\text { Some supermarkets will alter the labels of products that are about } \\
\text { to expire. } \\
\text { I: How do you know the date has been changed? } \\
\text { P: Because one of my daughters work in a supermarket. She told } \\
\text { me that their supermarket often secretly altered the labels of } \\
\text { goods that are about to expire, and then continue to sell them. }\end{array}$ & $\begin{array}{l}\text { I will look at labels carefully and will not visit small } \\
\text { supermarkets. }\end{array}$ \\
\hline $\begin{array}{l}\text { P21, female, } 57 \text {, } \\
\text { rural }\end{array}$ & Substitution & $\begin{array}{l}\text { I bought fake beef in the farmer's market before ... The normal } \\
\text { beef costs more than } 50 \text { CNY per kilogram, and the merchant } \\
\text { sold it for } 36 \text { CNY. My husband ate it and thought it was fake } \\
\text { too, maybe it was made from other meat. }\end{array}$ & I didn't buy too much at that time, so I ate them all anyway ... \\
\hline $\begin{array}{l}\mathrm{P} 20 \text {, male, } 46 \text {, } \\
\text { rural }\end{array}$ & Counterfeit & $\begin{array}{l}\text { I bought fake liquor in Shanghai. I knew it was fake because I felt } \\
\text { headache and had blurred vision after drinking it. }\end{array}$ & $\begin{array}{l}\text { I threw the fake liquor away. I didn't report the problem to the } \\
\text { supplier, it was in Shanghai. }\end{array}$ \\
\hline $\begin{array}{l}\text { P22, male, } 64, \\
\text { rural }\end{array}$ & Counterfeit & $\begin{array}{l}\text { I don't drink very often now, as there are too many fake liquors. } \\
\text { When I was a truck driver, I used to transport fake Erguotou (a } \\
\text { popular liquor brand). In the past, many breweries in Beijing } \\
\text { would recycle transparent liquor bottles, clean them and then } \\
\text { refill them with liquor from their own breweries. }\end{array}$ & I don't work as a truck driver anymore and I seldom drink. \\
\hline $\begin{array}{l}\text { P26, female, } 41 \text {, } \\
\text { rural }\end{array}$ & Counterfeit & I used to work in a hotel and many liquor $r$ bottles were recycled. & I don't drink and I don't work there anymore. \\
\hline $\begin{array}{l}\text { P26, female, } 41 \text {, } \\
\text { rural }\end{array}$ & $\begin{array}{l}\text { Addition; Passing off spoilt, } \\
\text { diseased meat as quality } \\
\text { products }\end{array}$ & $\begin{array}{l}\text { I once bought pork from the market with many small particles on } \\
\text { the skin of the pork. }\end{array}$ & $\begin{array}{l}\text { I returned the pork to the seller and won't buy meat products from } \\
\text { there anymore. Now I often go to the supermarket, I think it's a } \\
\text { relatively safe channel. I will also avoid buying any meat that are } \\
\text { reported to be risky during the period such as swine fever or bird } \\
\text { flu. }\end{array}$ \\
\hline $\begin{array}{l}\text { P27, female, 25, } \\
\text { rural }\end{array}$ & & I bought water-injected meat in the supermarket. & $\begin{array}{l}\text { I've learnt to distinguish water-injected meat now as its colour is } \\
\text { different from that of normal pork. }\end{array}$ \\
\hline $\begin{array}{l}\text { P29, female, } 48, \\
\text { rural }\end{array}$ & & I have bought water-injected beef in the supermarket before. & $\begin{array}{l}\text { I finished the beef (laugh) ... If it doesn't affect my health, I will } \\
\text { eat it up. }\end{array}$ \\
\hline
\end{tabular}

with different strokes. If you look carefully, you can easily distinguish between them. But if you just buy it in a hurry, you will probably take the imitation.' (P2, female, 33, urban)

'Usually I do not buy those without any of those safety and quality qualifications. The more symbols to me (laugh) ... the better. I will also check the seal but usually there is no problem especially for those big brands.' (P8, female, 53, urban)

'I'll look at the production date, the shelf life and see if it's labelled genetically modified.' (P20, male, 46, rural)

P7: Well, basically I rely on the labels now ... Unless someone manipulate the labels, there's nothing I could do, but based on the labels, especially the labels of the English version that is really, really a great source of information for me because at least I've got the advantage of the English language so I can trace back to the English version as my major source of reference so I can, well if it's really from Spain and which part of Spain has it been produced' (P7, male, 37, urban).

Participants rely on information from the internet, television and online reviews and recommendations from family and friends. They were more sceptical of information from social media such as WeChat and Weibo unless it is been shared via a public official account.
Information from family members and friends were valued and often trusted. Participants were willing to try different, new brands if recommended by their family members or peers.

'I get information from a wide range of sources, for instance, recommendations from friends, family members and online reviews and my common sense. It's like a hybrid decision making process.' (P7, male, 37, urban)

'I trust the bigger brands maybe because of their TV commercials. I think if those producers can afford very expensive TV commercials, then they can get their quality better. That is another point which I will always consider.' (P30, female, 49, urban)

'I will check public information on the internet or get information from friends, but I don't trust the information on WeChat.' (P16, female, 39, urban)

'I often talk with my neighbours about which food products are good and which ones are not good.' (P11, female, 59, rural)

\subsection{Daily self-preservation strategies}

Participants preferred to cook at home where possible and avoid 
street food. Most rural participants were able to grow vegetables and fruits or have easier access to fresh produce from their community. Some rural participants made their own oil, hence protecting themselves against risk of gutter oil.

'I cook at home. I also make soymilk and occasionally grow bean sprouts by myself. I don't dare to buy bean sprouts outside because they are grown with chemicals.' (P2, female, 33, urban).

'I'm a farmer and grow my own rice and corn. I don't need to buy cooking oil. I use peanuts and rapeseed to make oil myself. I also have a sister-inlaw. She raises pigs and sell pork to me.' (P11, female, 59, rural)

'I will buy pork to make lard oil myself.' (P23, female, 72, rural)

During food preparation, participants tend to add salt, baking powder or detergent to wash fruits and vegetables. Some tend to reuse the water used to clean rice, whilst others resort to washing their produce a few times and would peel fruits prior to consumption. Some urban consumers resort to using meat and fresh produce cleaning devices. However, participants 7 and 30 were against using such devices as they felt the machines were useless and part of a scam.

'I would rinse my fruits and vegetables thoroughly and soak them in baking soda. I was recommended a cleaning detergent for fruits and veggies but I've only used that twice. Not quite sure if it's useful. My mum even bought a veggie fruit washing machine that is helpful for getting rid of chemicals. Who knows ... But I'm not a fan of chemical products, so I usually choose baking soda powder, as long as it's edible, it won't be that detrimental to one's health.' (P7, male, 37, urban)

'Now many vegetables contain pesticides and chemicals, so I bought a special machine to wash vegetables and fruits. I also use an ozone machine to deal with meat products. I put the meat in water and then use the ozone machine to clean it. There will be a lot of foam if the quality of the meat product is not good. The machine is recommended by my friends.' (P16, female, 39, urban)

'I'll soak the vegetables in water or use a special vegetable detergent. I will try to avoid eating raw vegetables. If I want to eat fruits such as apples and pears, I would wash them and peel them.' (P20, male, 46, rural)

'We used to have a vegetable washing machine, but later it proved to be a fake concept. We learned from the news that it was a scam. It's cheating ... there will always be clever people who are very good at selling all kinds of health-related concepts to dip into people's pockets.' (P30, urban, 49, urban)

Most participants, especially rural consumers, rarely eat out and if they were to dine out, they will opt for time-honoured (reputable) restaurants. Urban participants would also make their selection based on the number of patrons, online reviews, kitchen hygiene and outer appearance. None of the participants mentioned observation of official inspection certificates or food safety grades. There's also a high level of trust towards global fast food chains such as KFC, McDonald's and Pizza Hut.

'If the dishes are mixed with gutter oil, most people will not be aware of it unless it is exposed on the news. So, now we choose bigger and qualityassured restaurants to avoid gutter oil. Now online reviews are available, so I will refer to the reviews and choose better restaurants.' (P2, female, 33 , urban)

'When I go out to restaurants, to be honest, I just blind my eyes and eat. I don't like to go out to eat in restaurants because you know, always there will be news that expose some food fraud or at least unclean food. So yeah, I just closed my eyes. And it's definitely not as good as what we make at home.' (P5, female, 27, urban)

'I don't normally eat out. I almost always cook at home as I don't trust the ingredients the restaurant used. I just feel that if I cook at home the taste is lighter and the food is cleaner.' (P24, female, 58, rural)

\section{Discussion}

The overall sense of discontent echoed previous studies who reported widespread sense of insecurity and distrust in local food. The insecurity was fuelled by food products being adulterated with illegal additives and excessive pesticide residues that cannot be easily detected or corrected by hygienic food handling strategies at home (Klein, 2013; Veeck, Veeck, \& Zhao, 2015; Zhu et al., 2017). Kendall et al. (2019) reported similar examples of incidents recalled by consumers in which they perceived the food that they had purchased or consumed to be subjected to fraud such as mislabelling, artificial enhancement with food additives, excessive pesticides and hormones, substitution with other meat species and counterfeit brands. The rural consumers in this study also showed concern for food safety risks due to fake and unsafe food products. This contradicts Holtkamp et al. (2014) and Liu and McGuire (2015) who reported that rural residents showed less concern about food safety risks. These previous studies collated data from media and interviews with regulatory bodies and heads of local townships. Our findings from detailed semi-structured interviews with rural residents marks an important reference point in food fraud awareness and concern among rural consumers. It also revealed that rural consumers have developed agile coping mechanisms and strategies to protect themselves against purchasing and consuming fraudulent food products.

The findings in this study also reflect previous study by Liu and Niyongira (2017) where consumers preferred to buy food from supermarket and paid more attention to expiry date on food label. Middleclass, urban consumers often sought for safer and alternative food choices such as locally grown organic fresh produce and were willing to pay more (Pritchard \& Chan, 2017; Veeck et al., 2015). All participants in this study frequently washed and soaked fresh produce with salt, baking powder, rice water (water used to wash rice), or flour prior to cooking and would peel pome fruits before consumption. Similarly, Klein (2013) investigated how consumers in Kunming acted upon food safety threats especially pesticides and chemical fertilisers in fresh produce and found that consumers would choose, soak, wash and taste vegetables for sign of pesticide residues. Si, Regnier-Davies, and Scott (2018) reported similar coping strategies practised by consumers in Nanjing who would wash and soak fresh produce in water, rice water, salt and other cleaning agents to remove chemical residues and bacteria.

Although none of the interviewees here travelled to Hong Kong to purchase foreign, branded infant formula, some used daigous and imported milk remain a priority among Chinese consumers (China Daily, 2011). The interviewees preferred to purchase foreign brands from large supermarkets, online or rely on family and friends who travelled abroad to purchase infant formula. Chinese consumers still lack confidence in domestically produced infant formulas and concerned parents in China often sourced for foreign-produced infant formula (El Benni et al., 2019; Hanser \& Li, 2015; Li, Sijtsema, Kornelis, Liu, \& Li, 2019a; 2019b). Chinese consumers preferred imported milk powder from abroad such as United States, United Kingdom, New Zealand, Australia and Switzerland compared to domestic milk powder. If the price of milk is too low, consumers consider the milk to be inferior quality and is unacceptable. Wang, Gao, Heng, and Shi (2019) reported that country of origin and price were two of the most important indicators of milk safety. El Benni et al. (2019) found that Chinese consumers were more likely to purchase milk products with a protected designation of origin (PDO) label compared to milk products without this label. Authenticity cues such as labelling, branding, quality certification, price, seals and barcodes were used by consumers as strategies against purchasing fraudulent food products (Kendall et al., 2019). A few of the urban participants used trusted daigous to purchase milk powder on their behalf. Daigou services represent a lucrative grey 
market for infant formula and health supplements. For example, up to 30,000 packages of Australian-made baby formula products were shipped to China per day (Cooper, 2018; Puddy \& Burnie, 2018).

There is also a high level of trust towards small vegetable vendors and farmers among the participants especially if they knew the sellers and were aware that the sellers were also producing the fresh produce for self-consumption. Farmers were found to practise a self-protection mechanism by adopting a 'one-family-two-cultivation-system' where safe, healthy food that are not treated with chemicals were used for own consumption, for relatives and people with close social ties, while unsafe and lesser quality produce was sold to strangers in the market (Lin, Fang, Zhou, \& Xu, 2018; Si, Li, Fang, \& Zhou, 2018). This is still prevalent among the rural participants as Chinese rural villages are still very much an 'acquaintance society' - a society where everyone is familiar with everyone else (Xiong \& Payne, 2017).

Although some of the participants did not trust the information shared on social media, the media plays an increasingly important role in exposing food fraud and food safety problems and allows rapid dissemination of information. Food scandals exposed by We-media (micro blogs such as WeChat, Weibo) were found to affect consumers' purchasing behaviour such as distrust and avoidance of the affected food and negative association with the brand (Peng, Li, Xia, Qi, \& Li, 2015). Social relationships play an important role in the social lives of Chinese consumers. The Chinese community invest a high level of personal trust in people who are in their social network ranging from family, relatives, local community and the wider network of friends (Yan, 2012).

Even though most participants in this study rarely eat out, if they do, they would opt for international fast food chains or reputable or familiar restaurants. They relied on online reviews, recommendations from family or friends and would observe the restaurant environment i.e. level of hygiene and number of patrons. The findings reflect Bai, Wang, Yang, \& Gung (2019) where consumers relied on 'word of mouth' and restaurant environment such as the cleanliness as an indicator of restaurant food safety. The level of crowdedness of a restaurant was also used as an indicator when selecting a restaurant (Ha, Park, \& Park, 2016). Bai, Wang, Yang, and Gong (2019) found that Chinese consumers did not make use of the food safety grade notifications when evaluating a restaurant's food safety level. In Beijing, restaurants are graded according to two levels: (i) environment grade such as the layout of buildings, facilities and equipment; and (ii) management grade such as incoming inspection, processing, cleaning and disinfecting. A, B or C is used to represent the environment grade of 'excellent', 'good' or 'pass' while star pictures are used to represent the management grade. Three stars = 'excellent', two stars = 'good' and one star $=$ 'pass'. Although the food safety grades may be one of the most reliable indicators of food safety, consumers may not be aware of such ratings due to lack of publicity or understanding of the grading procedures (Bai et al., 2019). Another reason could be due to a lack of trust in the food safety regulatory system and the possibility of fraudulent ratings posed in restaurants.

\section{Conclusion}

The results showed that consumers had experienced or witnessed different types of fraud such as alteration of expiry dates in supermarkets or were part of the fraudulent food supply chain (i.e. recycling of liquor bottles). Both urban and rural consumers were anxious, insecure and uncertain about the state of food products in the country. This has driven distrust in the food system, hence Chinese consumers have developed risk mitigating strategies against purchasing and consuming fraudulent food products. The coping approaches include purchasing strategies such as buying foreign-branded food products, purchasing from large supermarkets or sourcing for fresh produce directly from trusted vegetable vendors or farmers. Consumers too utilised sensory perceptions such as visual appearance, smell and texture whilst selecting food products. The findings also highlighted that consumers practised information searching strategies such as being attentive to expiry dates, brands and country of origin and often recommended suitable food products or restaurants to their social network. Daily selfpreservation strategies such as washing and soaking of fresh produce were carried out to remove pesticide residues. Rural consumers were more self-sufficient and were able to farm and produce their own oil to avoid the risk of consuming gutter oil. Despite previous researchers stating that rural consumers were less aware of food safety risks, the rural consumers in this study showed concern for food safety risks due to fake and unsafe food products. This study establishes an important point of reference where rural consumers have developed agile coping mechanisms against food fraud and are highly sensitised to food safety risks due to fraudulent products. The government and food industry should consider strengthening dissemination of information about safe food to rebuild consumers' trust.

\section{CRediT authorship contribution statement}

Jan Mei Soon: Conceptualization, Data curation, Formal analysis, Investigation, Methodology, Project administration, Writing - original draft. Xin Liu: Data curation, Investigation, Methodology, Writing original draft.

\section{Declaration of competing interest}

The authors declare that they have no known competing financial interests or personal relationships that could have appeared to influence the work reported in this paper.

\section{Acknowledgements}

The authors are grateful for the financial support from Sino-British Fellowship Trust and British Academy. This publication reflects the views of the authors, and funders cannot be held responsible for any use of the information contained in the publication.

\section{References}

Bai, L., Wang, M., Yang, Y., \& Gong, S. (2019). Food safety in restaurants: The consumer perspective. International Journal of Hospitality Management, 77, 139-146.

BBC (2014). China suspends McDonald's and KFC's meat supplier. Available at: https:// www.bbc.co.uk/news/business-28399162, Accessed date: 18 December 2019.

Braun, V., \& Clarke, V. (2006). Using thematic analysis in psychology. Qualitative Research in Psychology, 3(2), 77-101.

Braun, V., Clarke, V., Hayfield, N., \& Terry, G. (2019). Thematic analysis. In P. Liamputtong (Ed.). Handbook of research methods in health social sciences (pp. 843860). Singapore: Springer Singapore.

China Daily (2011). Mainland buyers snap up baby milk powder. Available at: http:// www.china.org.cn/business/2011-02/14/content_21913309.htm, Accessed date: 19 December 2019.

Cooper, L. (2018). Chinese 'daigou' buyers shipping 30,000 Australian baby formula packages overseas a day. 9 News. 3 December. Available at: https://www.9news. com.au/national/australia-baby-formula-chinese-buyers-daigous-30000-packagesper-day-a2-milk/d4524898-1b1c-4b8a-b526-fa8bfae470e0, Accessed date: 30 December 2019.

Delman, J., \& Yang, M. (2012). Chapter 13. A value chain gone awry: Implications of the "tainted milk scandal" in 2008 for political and social organization in rural China. In A. Bislev, \& S. Thogersen (Eds.). Organizing rural China, rural China organizing (pp. 205-222). Plymouth, UK: Lexington Books.

Duggan, J. (2015). China's middle class turns to organics after food safety scares. The Guardian. 14 May 2015. Available at: https://www.theguardian.com/sustainable business/2015/may/14/china-middle-class-organics-food-safety-scares, Accessed date: 1 January 2020.

El Benni, Stolz, H., Home, R., Kendall, H., Kuznesof, S., Clark, B., et al. (2019). Product attributes and consumer attitudes affecting the preferences for infant milk formula in China - a latent class approach. Food Quality and Preference, 71, 25-33.

Hanser, A., \& Li, J. C. (2015). Opting out? Gated consumption, infant formula and China's affluent urban consumers. The China Journal, 74, 110-128.

Ha, J., Park, K., \& Park, J. (2016). Which restaurant should I choose? Herd behaviour in the restaurant industry. Journal of Foodservice Business Research, 19(4), 396-412.

Holtkamp, N., Liu, P., \& McGuire, W. (2014). Regional patterns of food safety in China: What can we learn from media data? China Economic Review, 30, 459-468.

Kang, Y. (2019). Food safety governance in China: Change and continuity. Food Control, 106, 106752. 
Kendall, H., Kuznesof, S., Dean, M., Chan, M.-Y., Clark, B., Home, R., et al. (2019) Chinese consumer's attitudes, perceptions and behavioural responses towards food fraud. Food Control, 95, 339-351.

Kendall, H., Naughton, P., Kuznesof, S., Raley, M., Dean, M., Clark, B., et al. (2018). Food fraud and the perceived integrity of European food imports into China. PLoS One, 13(5), e0195817.

Klein, J. A. (2013). Everyday approaches to food safety in Kunming. The China Quarterly, 214, 376-393.

Lam, H.-M., Remais, J., Fung, M.-C., Xu, L., \& Sun, S.-M. (2013). Food supply and food safety issues in China. The Lancet, 381(9882), 2044-2053.

Lin, H., Fang, P., Zhou, L., \& Xu, L. (2018). A relational view of self-protection amongst China's food safety crises. Canadian Journal of Development Studies, 40(1), 131-142.

Li, S., Sijtsema, S. J., Kornelis, M., Liu, Y., \& Li, S. (2019a). Consumer confidence in the safety of milk and infant formula in China. Journal of Dairy Science, 102(10), 8807-8818.

Liu, P., \& Ma, L. (2016). Food scandals, media exposure, and citizens' safety concerns: A multilevel analysis across Chinese cities. Food Policy, 63, 102-111.

Liu, A., \& Niyongira, R. (2017). Chinese consumers food purchasing behaviors and awareness of food safety. Food Control, 79, 185-191.

Li, S., Zhu, C., Chen, Q., \& Liu, Y. (2019b). Consumer confidence and consumers' preferences for infant formulas in China. Journal of Integrative Agriculture, 18(8), 1793-1803.

Liu, P., \& McGuire, W. (2015). One regulatory state, two regulatory regimes: Understanding dual regimes in China's regulatory state building though food safety. Journal of Contemporary China, 24(91), 119-136.

Lu, F., \& Wu, X. (2014). China food safety hits the "gutter". Food Control, 41, 134-138.

Maguire, M., \& Delahunt, B. (2017). Doing a thematic analysis: A practical, step-by-step guide for learning and teaching scholars. AISHE-J: The All Ireland Journal of Teaching and Learning in Higher Education, 9(3), 2017.

Pei, X., Tandon, A., Alldrick, A., Giorgi, L., Huang, W., \& Yang, R. (2011). The Chin melamine milk scandal and its implications for food safety regulation. Food Policy, 36(3), 412-420.

Peng, Y., Li, J., Xia, H., Qi, S., \& Li, J. (2015). The effects of food safety issues released by we media on consumers' awareness and purchasing behavior: A case study in China. Food Policy, 51, 44-52.

Pritchard, B., \& Chan, Y. W. (2017). The new consumer politics of food in East Asia: Food safety, food scares and 'eating right'. Asia Pacific Viewpoint, 57(3), 297-300.

Puddy, R., \& Burnie, R. (2018). China's thirst for baby formula creating problems for Australian shoppers and staff. ABC News. 11 December. Available at: https://www. abc.net.au/news/2018-12-11/abc-investigation-uncovers-chinese-baby-formulashoppers/10594400, Accessed date: 30 December 2019.
Riccioli, F., Moruzzo, R., Zhang, Z., Zhao, J., Tang, Y., Tinacci, L., et al. (2020). Willingness to pay in main cities of Zhejiang province (China) for quality and safety in food market. Food Control, 108, 106831.

Roberts, M., \& Lin, C.-F. (2016). China food law update: The 2015 Food Safety Law and social governance on food safety. Journal of Food Law and Policy, 12(2), 1-35.

Silverman, D. (2006). Interpreting qualitative data: Methods for analyzing talk, text and interaction. London, UK: Sage.

Si, Z., Li, Y., Fang, P., \& Zhou, L. (2018). "One family, two systems": Food safety crisis as a catalyst for agrarian changes in rural China. Journal of Rural Studies, 69, 87-96.

Si, Z., Regnier-Davies, J., \& Scott, S. (2018). Food safety in urban China: Perceptions and coping strategies of residents in Nanjing. China Information, 32(2), 377-399.

Spink, J., \& Moyer, D. C. (2011). Defining the public health threat of food fraud. Journal of Food Science, 76(9), R157-R163.

Veeck, G., Veeck, A., \& Zhao, S. (2015). Perceptions of food safety by urban consumers in Nanjing, China. The Professional Geographer, 67(3), 490-501.

Wang, E., Gao, Z., Heng, Y., \& Shi, L. (2019). Chinese consumer' preferences for food quality test/measurement indicators and cues of milk powder: A case of Zhengzhou, China. Food Policy, 89, 101791.

Watts, J. (2004). Chinese baby milk blamed for 50 deaths. The Guardian. 21 April. Available at: https://www.theguardian.com/world/2004/apr/21/china.jonathanwatts, Accessed date: 19 December 2019

Wei, L., Pei, J., Zhang, A., Wu, X., Xie, Y., \& Yang, Y. (2020). Application of stochastic Bayesian modeling to assess safety status of baby formulas and quantify factors leading to unsafe products in China market. Food Control, 108, 106826.

Wu, X., Lu, Y., Xu, H., Lv, M., Hu, D., He, Z., et al. (2018). Challenges to improve the safety of dairy products in China. Trends in Food Science \& Technology, 76, 6-14.

Xie, Z. (2018). Im/materializing cross-border mobility: A study of mainland China-Hong Kong daigou (cross-border shopping services on global consumer goods). International Journal of Communication, 12, 4052-4065.

Xiong, H., \& Payne, D. (2017). Characteristics of Chinese rural networks: Evidence from villages in central China. Chinese Journal of Sociology, 3(1), 74-97.

Yan, Y. (2012). Food safety and social risk in contemporary China. Journal of Asian Studies, 71(3), 705-729.

Yasuda, J. K. (2015). Why food safety fails in China: The politics of scale. China Quarterly, 223, 745-769.

Zhang, L., Xu, Y., Oosterveer, P., \& Mol, A. P. J. (2016). Consumer trust in different food provisioning schemes: Evidence from Beijing, China. Journal of Cleaner Production, 134(Part A), 269-279.

Zhu, H., Jackson, P., \& Wang, W. (2017). Consumer anxieties about food grain safety in China. Food Control, 73(Part B), 1256-1264. 